\title{
Effect of physiotherapy with locomotor training with partial body weight on the gait kinematics of stroke patients
}

\author{
Elisangela F Manffra ${ }^{1 *}$, Tatiane C Boumer ${ }^{1}$, Gisele F Devetak ${ }^{1,2}$ and Ana PC Loureiro ${ }^{3}$ \\ ${ }^{1}$ Health Technology Graduation Program, Pontifícia Universidade Católica do Paraná (PUCPR), Brazil \\ ${ }^{2}$ Complexo Hospital de Clínicas, Universidade Federal do Paraná (UFPR), Brazil \\ ${ }^{3}$ School of Life Sciences , Pontifícia Universidade Católica do Paraná (PUCPR), Brazil
}

\begin{abstract}
The recovery of independent walking is a major objective of post-stroke rehabilitation and different therapeutic modalities are employed, as the Locomotor Training with Body Weight Support (LTBWS). To evaluate their effect on gait kinematics one might rely on gait analysis with summary indexes such as the Gait Profile Score (GPS). The aim of this work was to evaluate the effect of associating the LTBWS with conventional therapy on the gait quality of post-stroke patients, using GPS as the main outcome measure. To do this, a randomized clinical trial was performed with a sample of 16 participants, mean age 53.3 ( \pm 8$)$ years, 7 male and 9 female, post-stroke 6.8 average time $( \pm 5.7)$ months. To analyze the effects of LTBWS, participants were randomly allocated in two groups, the control (CG) and experimental (EG) groups, with 7 and 9 participants, respectively. The CG received only conventional physical therapy once or twice a week and the EG, received additional 20 minutes of LTBWS conducted on a treadmill (10 minutes) and on the ground (10 minutes) for 12 weeks. No difference between groups was found. Within CG, none of the variables exhibited differences between the moments. Within EG, the GPS of the both limbs and GPS of paretic limb, changed post-intervention. However, some individuals presented improvement above the minimal detectable change in both groups. In conclusion, associating LTBWS with physical therapy seems to be not superior than conventional physical therapy, but it deserves more investigation in larger samples as there were some individuals that responded better than others.
\end{abstract}

\section{Introduction}

After a stroke, the gait rehabilitation becomes essential not only to improve functional independence, but also to promote social interaction and quality of life of this population [1].

Usually, the physiotherapists use parallel bars, orthoses and/ or mobility aids such as walkers, crutches or canes for gait training. However, these strategies require some degree of postural control and muscle strength, and demand high energy expenditure, leading to fatigue after few minutes [2,3]. Besides, due to the patients fear and risk of falling, the require attention and aid of the physiotherapists leading to their physical exhaustion, as well. A therapeutic alternative for gait training in this population is the use of partial weight support during gait, thus reducing the energy expenditure and increasing safety [4].The use of body weight support equipment, associated with the guidance and feedback of physiotherapists, has been proposed in different studies focused on rehabilitation of gait after stroke, several of them with positive outcomes [5-9], pointing out several benefits, such as the evolution of locomotor capability [10] and improved symmetry and trunk control [11]. However, part of the existing studies in the literature that analyzed and compared Locomotor Training With Body Weight Support (LTBWS) with other forms of physiotherapy [12-15], have led different conclusions and there is still no consensus on the superiority of LTBWS in comparison with other approaches.

This lack of superiority over other therapeutic approaches was widely discussed in a critical review which recommended randomized clinical studies should address the effect of the combination of different therapeutic modalities [16] rather than isolated techniques as was being done so far.
The LTBWS facilitates gait initiation [17] and generates positive impacts on spatiotemporal gait parameters such as step symmetry [18], especially when combining treadmill and ground training. In this context, we consider relevant to investigate the effects of association of conventional physical therapy and a LTBWS on treadmill and over ground.

During the training, the patient is not only stimulated to walk fast but also to move the limbs as correctly and coordinated as possible. Therefore, we have chosen to perform a three-dimensional gait analysis data (3DGA) to assess the effects of the training. This type of evaluation is considered effective in the quantification of changes in ambulation of patients in general [19], providing significantly useful measures for clinical practice and providing objective information on changes in movement patterns [20]. Among all the possible measures that can be derived from 3DGA, we selected the Gait Profile Score (GPS) as our main outcome measure. It is calculated from angular data of gait kinematic pattern, developed in order to facilitate the understanding of the results 3DGA $[20,21]$. The advantage of its use is the possibility to analyze the joints individually, as well as offering an individual

${ }^{*}$ Correspondence to: Elisangela Ferretti Manffra, Health Technology Graduate Program- Pontifical Catholic University of Paraná, Tel: +5541- 984040690, Brazil, E-mail: elisangela.manffra@pucpr.br

Key words: stroke, walk, gait profile score, locomotor training, weight support

Received: September 11, 2019; Accepted: October 10, 2019; Published: October 14,2019 
score for each of the lower limbs of the evaluated subject, as well as an absolute global representation score of their gait pattern [20]. Two experiments have been applied the GPS on post-stroke subjects $[22,23]$, one of them determined the minimum detectable change (MDC) to these subjects [22].

Thus, the aim of this work was to evaluate the effectiveness of a program for gait training after stroke, associating conventional physiotherapy and the LTBWS on treadmill and over ground, using the GPS as the main outcome measure.

\section{Methods}

\section{Study design}

This study was planned as a prospective, assessor-blind, randomized controlled pragmatic clinical trial, and was approved by the Research Ethics Committee of the University (process number: 256.523/2013). It followed the Consolidated Standards of Reporting Trials (CONSORT) recommendations and was registered in the Brazilian Register of Clinical Trials (ReBEC - RBR-7699xz). The study was carried out at the Ana Carolina Moura Xavier Rehabilitation Hospital between February of 2014 and March of 2015. All participants provided written informed consent.

\section{Sample}

To be included in the study, participants should be over 18 years old, should present paresis in one lower limb, should be able to understand the instructions for performing the gait analysis and to walk at least $10 \mathrm{~m}$ without assistance of another person. The exclusion criteria were bilateral stroke, history or presence of other neurological or musculoskeletal disorders unrelated to stroke. The final sample was composed by 16 hemiparetic participants (mean age $53.3 \pm 8.0$ years; 7 men and 9 women; 7 hemiparetic at left and 9 at right side; mean time after stroke $6.8 \pm 5.7$ months) all with stroke diagnosis confirmed by neuroimaging. All participants received physical therapy treatment at the outpatient rehabilitation hospital. Other characteristics of the sample are given in table 1 .

Participants were randomly assigned to the experimental group (EG) or control group (CG) after initial evaluation. Randomization was performed using a table of pseudo-random numbers between 0 and 1 obeying a uniform distribution. The table was create using the software Matlab v.10. The randomization sequence was generated by a researcher not involved in recruitment nor in the assessment. The flowchart according to CONSORT depicture the steps of study (Figure 1).
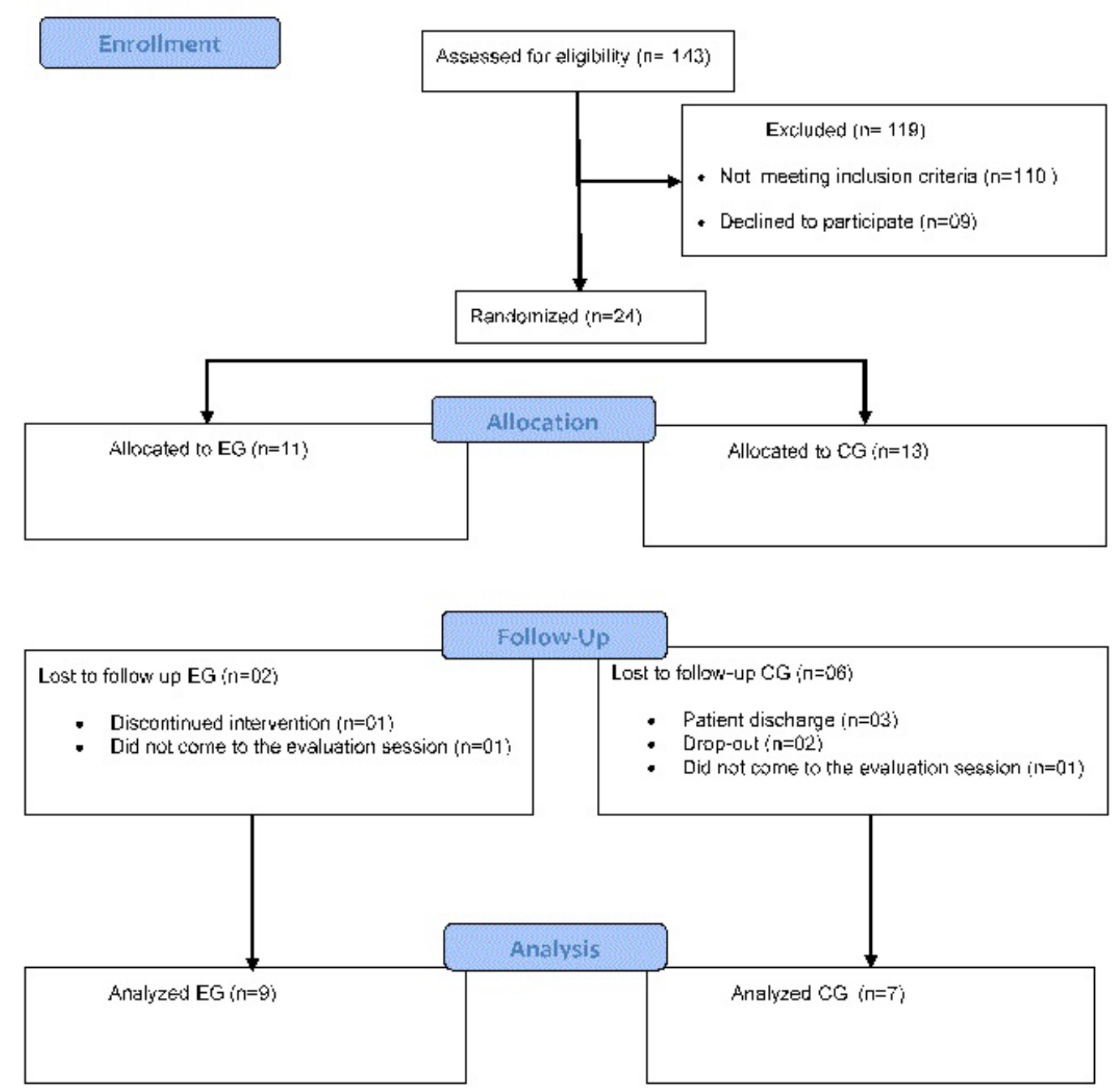

Figure 1. Study flowchart 
Table 1. Characteristics of the sample

\begin{tabular}{|c|c|c|c|c|c|c|c|c|c|c|}
\hline & ID & Group & Gender & Age (years) & Paretic Side & Type of Stroke & $\begin{array}{l}\text { Time since } \\
\text { stroke } \\
\text { (months) }\end{array}$ & $\begin{array}{l}\text { Initial FAC } \\
\text { values }\end{array}$ & Weight (kg) & Height (cm) \\
\hline 1 & B & CG & F & 52 & $\mathrm{R}$ & $\mathrm{H}$ & 3 & 1 & 67.8 & 156 \\
\hline 2 & $\mathrm{~F}$ & $\mathrm{CG}$ & $\mathrm{F}$ & 54 & $\mathrm{~L}$ & I & 6 & 4 & 58.4 & 160 \\
\hline 3 & $\mathrm{~K}$ & $\mathrm{CG}$ & M & 56 & $\mathrm{R}$ & $\mathrm{H}$ & 10 & 5 & 78.0 & 172 \\
\hline 4 & $\mathrm{~L}$ & $\mathrm{CG}$ & $\mathrm{F}$ & 59 & $\mathrm{R}$ & I & 7 & 4 & 60.6 & 158 \\
\hline 5 & $\mathrm{~S}$ & $\mathrm{CG}$ & $\mathrm{F}$ & 51 & $\mathrm{R}$ & I & 7 & 4 & 56.8 & 151 \\
\hline 6 & $\mathrm{U}$ & $\mathrm{CG}$ & $\mathrm{F}$ & 43 & $\mathrm{R}$ & I & 3 & 1 & 57.9 & 165 \\
\hline 7 & $\mathrm{X}$ & $\mathrm{CG}$ & M & 51 & $\mathrm{~L}$ & $\mathrm{H}$ & 11 & 5 & 76.0 & 166 \\
\hline 8 & $\mathrm{~A}$ & EG & $\mathrm{F}$ & 54 & $\mathrm{~L}$ & I & 10 & 3 & 67.5 & 161 \\
\hline 9 & $\mathrm{D}$ & EG & M & 63 & $\mathrm{~L}$ & I & 10 & 4 & 73.0 & 172 \\
\hline 10 & $\mathrm{E}$ & EG & M & 33 & $\mathrm{R}$ & I & 2 & 4 & 75.0 & 172 \\
\hline 11 & G & EG & M & 66 & $\mathrm{~L}$ & I & 6 & 3 & 93.5 & 177 \\
\hline 12 & I & EG & $\mathrm{M}$ & 64 & $\mathrm{R}$ & I & 5 & 3 & 67.8 & 162 \\
\hline 13 & $\mathrm{~J}$ & EG & $\mathrm{M}$ & 49 & $\mathrm{R}$ & I & 1 & 5 & 78.8 & 171 \\
\hline 14 & $\mathrm{~N}$ & EG & $\mathrm{F}$ & 53 & $\mathrm{~L}$ & $\mathrm{H}$ & 2 & 5 & 67.8 & 156 \\
\hline 15 & $\mathrm{O}$ & EG & $\mathrm{F}$ & 52 & $\mathrm{R}$ & $\mathrm{H}$ & 2 & 3 & 65.1 & 161 \\
\hline 16 & $\mathrm{R}$ & EG & $\mathrm{F}$ & 53 & $\mathrm{~L}$ & I & 24 & 5 & 64.8 & 154 \\
\hline
\end{tabular}

Abbreviations: ID: Identification of participants; CG: Control Group; EG: Experimental Group; FAC: Functional Ambulation Category; F: Female; M: Male; I: Ischemic; H: Hemorrhagic; L: Left; R: Right;

\section{Assessments}

All participants were evaluated before and after the intervention program by the same physiotherapist who was blind to their group. Berg Balance Scale (BBS) [24] was applied to evaluate the functional balance performance and the Functional Ambulation Category (FAC) [25] to assess the walking function. The participants underwent an instrumented gait assessment in the hospital's gait laboratory. Reflective markers were placed on the skin of the participants, according to the Helen Hayes Marker Set, and they were instructed to walk at a selfselected speed, on a $10 \mathrm{~m}$ path for 6 times (trials). Kinematic data were collected by 6 infrared cameras and a motion capture system (Motion Analysis Corporation, Santa Rosa, CA). The data were sampled at $60 \mathrm{~Hz}$ and low-pass filtered with a cut-off frequency of $6 \mathrm{~Hz}$ using a fourthorder digital Butterworth filter.

\section{GPS calculation}

Data from the first and second trials were discarded, to avoid the effect of adaptation, and the first valid strides of the next three trials were used for analysis. GPS calculations were performed according to the method reported by Baker and colleagues $[20,26]$ using the spreadsheet available in [27], after adapting it to analyze paretic and nonparetic limbs. Basically, the calculation of GPS requires the Gait Variable Score (GVS), which refers to the root mean square difference between the joint angles of each subject and the average of healthy subjects during a gait cycle. There are 15 GVS values, one for each degree of freedom: pelvic tilt, obliquity, and rotation; hip flexion/extension, adduction/ abduction, and rotation; knee flexion/extension; ankle dorsiflexion/ plantarflexion; and foot progression.

Both the GVS and GPS were obtained for the paretic limb (PL) and non-paretic limb (NPL). The overall GPS (GPS_O) was also calculated by averaging the values for both limbs. These variables were grouped in the Movement Analysis Profile (MAP), which was generated individually for each participant. The values shown in the MAP (Figure 2) refer to the median of the 3 gait cycles, from which the 15 GVS, the GPS of PL, GPS of NPL and overall (GPS_O) were calculated.

\section{Intervention Program}

Participants from both groups underwent 40 minutes of physiotherapy treatment offered by the rehabilitation hospital with the institution's physiotherapists and without any participation of the researchers. This intervention was classified as conventional physical therapy and consisted predominantly of passive mobilization and assisted exercises of upper limbs, trunk and lower limbs, over ground gait training with and without obstacles, exercise in bike ergometer, and balance training with and without visual feedback.

The experimental group underwent additional 20 minutes of a specific LTBWS program. Parameters such as the time, speed and weight bearing percentage at each LTBWS session, as well as the period of intervention were based on parameters from previously published studies $[7,28,29]$. To provide body weight support we have used a Biodex unweighing system model 945-480, and the treadmill was Embrex, model 570-L. Table 2 describes the details of the LTBWS program applied to experimental group.

\section{Data analysis}

Statistical analysis was performed using IBM SPSS for Windows, version 21.0 (Armonk, NY: IBM Corp. USA). Mann-Whitney U-test test was used to perform between-groups comparisons. Comparisons between pre and post-intervention data within each group were performed using the Wilcoxon test. Significance level was set at 0.05 . Values of GVS and GPS score are presented as median and Interquartile Range (IQR).

The difference between pre and post-intervention values was calculated and contrasted with previously established MDC values [22].

\section{Results}

Table 3 shows the GVS results and GPS index pre and postintervention for both groups. No statistically significant difference between groups was found. Within CG, none of the variables exhibited statistically significant differences between the moments. Within EG, only the variables GPS_O $(p=0.01)$, GPS_PL $(p=0.00)$ e GVS_Knee 
Table 2. Details of the LTBWS applied in the study.

\begin{tabular}{|l|l|}
\hline LTBWS Program & $\begin{array}{l}\text { - Period of program: } 12 \text { weeks; } \\
\text { - Frequency: once or twice a week, according to the schedule of physiotherapy sessions offered by Rehabilitation Hospital; } \\
\text { - In each LTBWS session participants underwent } 10 \text { minutes on treadmill and } 10 \text { minutes over ground. When the participant was not able to keep the } \\
\text { minimal velocity at the treadmill all the session time was spent training over ground. }\end{array}$ \\
\hline Velocity & $\begin{array}{l}\text { - Ground: comfortable self-selected speed; } \\
\text { - Treadmill: self-selected with a minimum of } 0.04 \mathrm{~m} / \mathrm{s} \text { (minimum possible speed of the treadmill model used in the study); } \\
\text { - Treadmill speed was increased with a step } 0.1 \mathrm{~m} / \mathrm{s} \text { according to the participants' evolution; }\end{array}$ \\
\hline Body weight offload & $\begin{array}{l}\text { - Initially, weight offload was established at } 40 \% \text { of the participant's weight; } \\
\text { - Offload was progressively reduced by } 5 \% \text { to zero, according to the participant's evolution; }\end{array}$ \\
\hline Protocol Considerations & - Participants received aid to move the paretic lower limb correctly, with emphasis on hip, knee and ankle flexion and correct foot positioning; \\
\hline
\end{tabular}

Table 3. Gait Variable Score (GVS) and Gait Profile Score (GPS) pre and post intervention presented as median (interquartile range)

\begin{tabular}{|c|c|c|c|c|c|}
\hline & \multirow{3}{*}{ Variable } & \multicolumn{2}{|c|}{ Control Group } & \multicolumn{2}{|c|}{ Experimental Group } \\
\hline & & \multicolumn{2}{|c|}{ Median (IQR) } & \multicolumn{2}{|c|}{ Median (IQR) } \\
\hline & & Pre & Post & Pre & Post \\
\hline \multirow{10}{*}{ 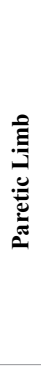 } & Pelvic Tilt & $9.6^{\circ}\left(7.5^{\circ}\right)$ & $5.2^{\circ}\left(5.9^{\circ}\right)$ & $6.0^{\circ}\left(3.7^{\circ}\right)$ & $4.9^{\circ}\left(5.0^{\circ}\right)$ \\
\hline & Hip Flexion/Extension & $16.6^{\circ}\left(17.6^{\circ}\right)$ & $13.4^{\circ}\left(7.5^{\circ}\right)$ & $13.2^{\circ}\left(5.0^{\circ}\right)$ & $12.4^{\circ}\left(4.8^{\circ}\right)$ \\
\hline & Knee Flexion/Extension & $20.8^{\circ}\left(6.8^{\circ}\right)$ & $19.8^{\circ}\left(5.4^{\circ}\right)$ & $20.0^{\circ}\left(5.4^{\circ}\right)$ & $18.5^{\circ}\left(6.0^{\circ}\right)$ \\
\hline & Ankle Dorsi/Plantarflexion & $11.8^{\circ}\left(2.1^{\circ}\right)$ & $10.6^{\circ}\left(3.5^{\circ}\right)$ & $10.3^{\circ}\left(3.2^{\circ}\right)$ & $9.9^{\circ}\left(4.9^{\circ}\right)$ \\
\hline & Pelvic Obliquity & $4.4^{\circ}\left(2.3^{\circ}\right)$ & $4.6^{\circ}\left(1.9^{\circ}\right)$ & $5.2^{\circ}\left(3.8^{\circ}\right)$ & $6.8^{\circ}\left(4.7^{\circ}\right)$ \\
\hline & Hip Adduction/Abduction & $5.1^{\circ}\left(1.5^{\circ}\right)$ & $4.4^{\circ}\left(1.6^{\circ}\right)$ & $4.8^{\circ}\left(1.9^{\circ}\right)$ & $4.7^{\circ}\left(3.1^{\circ}\right)$ \\
\hline & Pelvic Rotation & $14.8^{\circ}\left(11.6^{\circ}\right)$ & $13.5^{\circ}\left(15.3^{\circ}\right)$ & $8.6^{\circ}\left(5.9^{\circ}\right)$ & $9.3^{\circ}\left(6.2^{\circ}\right)$ \\
\hline & Hip Rotation & $8.5^{\circ}\left(10.1^{\circ}\right)$ & $5.8^{\circ}\left(4.3^{\circ}\right)$ & $8.7^{\circ}\left(15.3^{\circ}\right)$ & $6.9^{\circ}\left(5.4^{\circ}\right)$ \\
\hline & Foot Progression & $9.8^{\circ}\left(6.8^{\circ}\right)$ & $6.7^{\circ}\left(11.6^{\circ}\right)$ & $10.0^{\circ}\left(13.6^{\circ}\right)$ & $9.3^{\circ}\left(8.2^{\circ}\right)$ \\
\hline & GPS & $15.1^{\circ}\left(5.1^{\circ}\right)$ & $11.3^{\circ}\left(6.6^{\circ}\right)$ & $11.3^{\circ}\left(4.5^{\circ}\right)$ & $10.2^{\circ}\left(2.7^{\circ}\right)$ \\
\hline \multirow{11}{*}{ 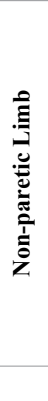 } & Pelvic Tilt & $9.6^{\circ}\left(7.5^{\circ}\right)$ & $5.2^{\circ}\left(5.9^{\circ}\right)$ & $6.0^{\circ}\left(3.7^{\circ}\right)$ & $4.9^{\circ}\left(5.0^{\circ}\right)$ \\
\hline & Hip Flexion/Extension & $16.4^{\circ}\left(7.7^{\circ}\right)$ & $15.4^{\circ}\left(7.5^{\circ}\right)$ & $17.8^{\circ}\left(6.4^{\circ}\right)$ & $13.4^{\circ}\left(7.4^{\circ}\right)$ \\
\hline & Knee Flexion/Extension & $25.3^{\circ}\left(3.3^{\circ}\right)$ & $24.1^{\circ}\left(5.6^{\circ}\right)$ & $24.1^{\circ}\left(4.8^{\circ}\right)$ & $24.5^{\circ}\left(6.7^{\circ}\right)$ \\
\hline & Ankle Dorsi/Plantarflexion & $15.0^{\circ}\left(9.6^{\circ}\right)$ & $16.2^{\circ}\left(4.5^{\circ}\right)$ & $16.5^{\circ}\left(3.8^{\circ}\right)$ & $15.7^{\circ}\left(4.3^{\circ}\right)$ \\
\hline & Pelvic Obliquity & $4.4^{\circ}\left(2.3^{\circ}\right)$ & $4.6^{\circ}\left(1.9^{\circ}\right)$ & $5.2^{\circ}\left(3.8^{\circ}\right)$ & $6.8^{\circ}\left(4.7^{\circ}\right)$ \\
\hline & Hip Adduction/Abduction & $6.3^{\circ}\left(4.4^{\circ}\right)$ & $6.8^{\circ}\left(4.3^{\circ}\right)$ & $6.1^{\circ}\left(1.8^{\circ}\right)$ & $6.1^{\circ}\left(3.4^{\circ}\right)$ \\
\hline & Pelvic Rotation & $14.8^{\circ}\left(11.9^{\circ}\right)$ & $13.5^{\circ}\left(15.3^{\circ}\right)$ & $8.6^{\circ}\left(5.9^{\circ}\right)$ & $9.3^{\circ}\left(6.2^{\circ}\right)$ \\
\hline & Hip Rotation & $10.4^{\circ}\left(12.2^{\circ}\right)$ & $11.4^{\circ}\left(7.4^{\circ}\right)$ & $7.2^{\circ}\left(4.6^{\circ}\right)$ & $5.6^{\circ}\left(4.2^{\circ}\right)$ \\
\hline & Foot Progression & $10.1^{\circ}\left(4.7^{\circ}\right)$ & $12.2^{\circ}\left(7.1^{\circ}\right)$ & $9.4^{\circ}\left(12.9^{\circ}\right)$ & $9.4^{\circ}\left(11.1^{\circ}\right)$ \\
\hline & GPS & $14.1^{\circ}\left(5.3^{\circ}\right)$ & $13.2^{\circ}\left(5.3^{\circ}\right)$ & $13.7^{\circ}\left(2.5^{\circ}\right)$ & $13.4^{\circ}\left(3.7^{\circ}\right)$ \\
\hline & GPS_O & $15.5^{\circ}\left(5.1^{\circ}\right)$ & $12.9^{\circ}\left(5.2^{\circ}\right)$ & $13.7^{\circ}\left(3.3^{\circ}\right)$ & $12.4^{\circ}\left(3.7^{\circ}\right)$ \\
\hline
\end{tabular}

Flexion/Extension PL $(p=0.01)$, were different between pre and postintervention.

Tables 4 and 5 depict the difference between MAP values pre and post-intervention for each subject in control and experimental groups, respectively. In these tables, the differences are contrasted with the MDC value from the literature [22].

The values of gait speed and BBS pre and post-intervention, for each group are shown in table 6 . There were no statistically significant differences between groups, and the comparison within groups revealed a gain in the BBS for CG $(p=0.034)$ and for EG $(p=0.012)$

Table 7 depicts the distribution of participants across the levels of the FAC. It is possible to observe that, in both groups there was a migration from lower to upper levels of FAC.

\section{Discussion}

Considering the comparisons between groups, we found no significant differences between them, but some other findings are worth to be discussed.

Observing table 4 , which presents the differences between pre and post-intervention for each participant in the CG, it can be observed that all of them, except $\mathrm{K}$, had at least one variable with difference above the MDC established in the literature [22]. Particularly, X presented improvement above the MDC in 5 variables (i.e. decrease in their values), including GPS_PL and GPS_O. This is interesting and surprising as this participant is in the chronic phase. It is well known that early post-stroke hypotonia gradually gives way to increased muscle tone, which usually evolves to hypertonia, thus changing the movement pattern of the involved segments and joints [30]. Three to four months after the occurrence of stroke, the changes caused by the pathology, such as hypertonia and hyperreflexia, are not yet fully established [31]. The chronic phase is characterized by neuromuscular changes that make physiotherapeutic conduct difficult and promote longer and more limited rehabilitation [32]. This phase, which begins around 5 to 6 months, continues throughout the patient's life. The behavior of this participant indicates that it is possible to promote improvement in gait pattern even in the chronic phase.

The other one participant $(S)$ showed improvement in four variables, but that did not impacted on the overall GPS , i.e. no significant change in global gait quality. This might reinforce the statement that there is no strong correlation between GVS's results and final GPS [20]. Participant (U) of the CG presented 5 variables with improvement and 3 variables with deterioration larger than the MDC. However, in the final GPS result, there was an improvement in both GPS_PL and GPS_O. 
Table 4. GVS and GPS differences between pre and post-intervention - Control Group

\begin{tabular}{|c|c|c|c|c|c|c|c|c|c|}
\hline \multirow{2}{*}{ Variables } & & & \multicolumn{7}{|c|}{ Control Group (Subject ID) } \\
\hline & & MDC & $1(\mathrm{~B})$ & $2(\mathrm{~F})$ & $3(\mathrm{~K})$ & $4(\mathrm{~L})$ & $5(\mathrm{~S})$ & $6(\mathrm{U})$ & $7(X)$ \\
\hline Pelvic Tilt & & 4.7 & $5.8^{\dagger}$ & -4.6 & -2.2 & 0.8 & 1.0 & -3.4 & $-5.4 *$ \\
\hline \multirow{2}{*}{ Hip Flexion/Extension } & PL & 5.4 & $6.7 \dagger$ & $7.0^{*}$ & -0.4 & -1.5 & 2.5 & $-17.6^{*}$ & $-6.4^{*}$ \\
\hline & NPL & 5.4 & 5 & -1.6 & -1 & -0.9 & -0.2 & -0.5 & -1.5 \\
\hline \multirow{2}{*}{ Knee Flexion/Extension } & PL & 5.3 & 3.9 & -1.5 & -0.7 & 1.7 & -0.2 & 1.0 & -1.0 \\
\hline & NPL & 3.1 & 1.8 & -1.6 & -2.3 & 2.1 & 2.1 & $3.7^{\dagger}$ & -2.5 \\
\hline \multirow{2}{*}{ Ankle Dorsi/Plantarflexion } & PL & 2.9 & 0.2 & 1.2 & -2.5 & 1.5 & $-4.6^{*}$ & 0.6 & -1.9 \\
\hline & NPL & 3.0 & 1.5 & -1.3 & 2.2 & -1.3 & 0.3 & -0.7 & 1.7 \\
\hline Pelvic Obliquity & & 2.4 & 0.3 & 0.3 & 1.1 & 1.3 & -1.7 & 0.0 & -0.1 \\
\hline \multirow{2}{*}{ Hip Adduction/Abduction } & PL & 3.1 & -0.7 & -0.5 & 0.1 & -1.1 & $-3.1^{*}$ & 1 & -1.7 \\
\hline & NPL & 2.8 & -2.3 & $3.2^{\dagger}$ & 0.6 & 1.7 & 0.3 & -1.2 & -1.4 \\
\hline Pelvic Rotation & & 5.0 & -1.2 & 1.7 & 1.6 & -2.4 & $-5.4^{*}$ & $5.0^{+}$ & -1.3 \\
\hline \multirow{2}{*}{ Hip Rotation } & PL & 10.0 & -1.2 & 1.7 & 1.6 & -2.4 & -5.4 & 5 & -1.3 \\
\hline & NPL & 7.4 & 2.8 & -7.2 & -0.8 & 2 & -1.5 & $-12.4 *$ & 1.6 \\
\hline \multirow{2}{*}{ Foot Progression } & PL & 6.2 & 1.7 & $-6.5^{*}$ & 1.2 & 0.7 & 1.7 & $-11.1^{*}$ & $-12.2 *$ \\
\hline & NPL & 4.1 & 1.9 & $9.8^{\dagger}$ & 1.4 & $8.3^{\dagger}$ & $-4.5^{*}$ & $5.5^{\dagger}$ & -0.2 \\
\hline \multirow{2}{*}{ GPS } & PL & 2.3 & $2.6^{\dagger}$ & -0.4 & -0.4 & 0.0 & -1.6 & $-3.1^{*}$ & $-4.1 *$ \\
\hline & NPL & 1.9 & 1.6 & 0.2 & -0.2 & 1.3 & -0.5 & -0.5 & -0.9 \\
\hline GPS_O & & 1.7 & $2.3^{\dagger}$ & -0.2 & -0.2 & 0.8 & -0.8 & $-2.2^{*}$ & $-2.7^{*}$ \\
\hline
\end{tabular}

Abbreviations: MDC: Minimal Detectable Change; PL: Paretic Limb; NPL: Non-Paretic Limb; ID, identification; GPS: Gait Profile Score; GPS_O: Gait Profile Score Overall;

Notes: Participants are identified by capital letters that match their identification in the previous tables.

Variables whose the difference between initial and final values exceed the MDC in bold. The symbols $(\dagger)$ and $\left({ }^{*}\right)$ indicate increasing and decreasing of index values, respectively. Reduction in index values denotes approximation of normal values.

Table 5. GVS and GPS differences between pre and post-intervention -Experimental Group

\begin{tabular}{|c|c|c|c|c|c|c|c|c|c|c|c|}
\hline \multirow{2}{*}{ Variables } & & & \multicolumn{9}{|c|}{ Experimental Group (Subject ID) } \\
\hline & & MDC & $1(\mathrm{~A})$ & $2(\mathrm{D})$ & $3(\mathrm{E})$ & $4(\mathrm{G})$ & $5(\mathrm{I})$ & $6(J)$ & $7(\mathrm{~N})$ & $8(\mathrm{O})$ & $9(\mathrm{R})$ \\
\hline Pelvic Tilt & & 4.7 & 0.3 & -0.3 & -2.2 & 0.8 & -0.5 & 0.2 & 2.8 & $11.8^{+}$ & -1.2 \\
\hline \multirow{2}{*}{ Hip Flexion/Extension } & PL & $\underline{5.4}$ & 2.8 & -1.1 & -0.3 & -3.0 & -0.5 & -5.1 & -0.3 & -3.6 & -0.7 \\
\hline & NPL & $\underline{5.4}$ & -5.1 & -1.3 & -3.3 & 0.6 & 1.3 & -5.1 & 2.1 & $10.9^{\dagger}$ & -0.1 \\
\hline \multirow{2}{*}{ Knee Flexion/Extension } & PL & $\underline{5.3}$ & $-6.0^{*}$ & -1.1 & 0.4 & -2.6 & -1.4 & $-5.1^{*}$ & -1.9 & -1.8 & -3.3 \\
\hline & NPL & $\underline{3.1}$ & 2.6 & -2.1 & $-5.0^{*}$ & $-4.2^{*}$ & -0.1 & $-5.9^{*}$ & 1.3 & -0.7 & -2.5 \\
\hline \multirow{2}{*}{ Ankle Dorsi/Plantarflexion } & PL & $\underline{2.9}$ & -0.4 & 1.8 & 3.0 & -0.5 & -1.9 & 0.8 & -2.4 & $-4.2^{*}$ & -2.3 \\
\hline & NPL & $\underline{3.0}$ & 1.9 & $3.2^{\dagger}$ & -1.3 & $-3.6^{*}$ & -2.6 & -1.9 & $5.3^{\dagger}$ & 2.1 & -0.7 \\
\hline Pelvic Obliquity & & $\underline{2.4}$ & -0.7 & -1.2 & $3.7^{\dagger}$ & $3.7^{\dagger}$ & $2.6^{\dagger}$ & 0.0 & 0.9 & 0.6 & -0.4 \\
\hline \multirow{2}{*}{ Hip Adduction/Abduction } & PL & $\underline{3.1}$ & -0.5 & -0.4 & -1.0 & $6.5^{\dagger}$ & $3.5^{\dagger}$ & -0.4 & 0.3 & 0.5 & -1.4 \\
\hline & NPL & $\underline{2.8}$ & $3.1^{\dagger}$ & 0.7 & 0.8 & 2.7 & 0.7 & 0.2 & -0.8 & -1.7 & 0.7 \\
\hline Pelvic Rotation & & $\underline{5.0}$ & 0.4 & 1.9 & -4.0 & 1.0 & 1.1 & -2.3 & 1.6 & -0.3 & -4.2 \\
\hline \multirow{2}{*}{ Hip Rotation } & PL & $\underline{10.0}$ & -0.8 & 3.5 & -1.5 & 2.5 & -6.8 & -1.6 & -2.4 & 1.4 & $20.7^{\dagger}$ \\
\hline & NPL & $\underline{7.4}$ & 1.9 & -0.6 & 0.6 & -2.7 & -6.2 & 1.8 & 0.1 & -0.8 & -1.8 \\
\hline \multirow{2}{*}{ Foot Progression } & PL & $\underline{6.2}$ & $-7.2^{*}$ & -5.0 & -0.3 & -1.6 & -0.7 & 1.2 & 4.0 & -2.8 & -3.7 \\
\hline & NPL & $\underline{4.1}$ & -3.7 & 1.0 & 2.3 & 1.5 & 3.6 & 1.6 & 1.5 & -3.8 & -3.9 \\
\hline \multirow{2}{*}{ GPS } & PL & $\underline{2.3}$ & -2.0 & -0.1 & -0.1 & -0.3 & -0.4 & -2.0 & -0.2 & $-2.3^{*}$ & $-5.5^{*}$ \\
\hline & NPL & $\underline{1.9}$ & -0.2 & 0.1 & -1.6 & -0.5 & 0.5 & -1.7 & 0.2 & $-3.0^{*}$ & -1.3 \\
\hline GPS_O & & 1.7 & -1.2 & -0.1 & -0.9 & -0.7 & 0.1 & $1.9^{*}$ & -0.2 & $-2.6^{*}$ & $-3.8^{*}$ \\
\hline
\end{tabular}

Abbreviations: MDC: Minimal Detectable Change; PL: Paretic Limb; NPL: Non-Paretic Limb; ID: identification; GPS: Gait Profile Score; GPS_O: Gait Profile Score Overall;

Notes: Participants are identified by capital letters that match their identification in the previous tables;

Variables whose the difference between initial and final values exceed the MDC in bold. The symbols $(\dagger)$ and $(*)$ indicate increasing and decreasing of index values, respectively. Reduction in index values denotes approximation of normal values.

Table 6. Gait velocity and score of the Berg Balance Scale (BBS)

\begin{tabular}{|c|c|c|c|c|}
\hline \multirow{3}{*}{ Measures } & \multirow{2}{*}{\multicolumn{2}{|c|}{$\begin{array}{c}\text { Pre } \\
\text { Median (IQR) }\end{array}$}} & \multirow{2}{*}{\multicolumn{2}{|c|}{$\begin{array}{c}\text { Post } \\
\text { Median (IQR) }\end{array}$}} \\
\hline & & & & \\
\hline & CG & EG & CG & EG \\
\hline Gait speed (average of PL and NPL) $(\mathrm{cm} / \mathrm{s})$ & $16.4(11.1)$ & $21.0(8.1)$ & $20.0(8.8)$ & $23.2(12.5)$ \\
\hline Gait speed of the Paretic Limb $(\mathrm{cm} / \mathrm{s})$ & $16.5(10.5)$ & $20.5(8.1)$ & $19.1(8.4)$ & $21.9(12.3)$ \\
\hline Gait speed of the Non-Paretic Limb $(\mathrm{cm} / \mathrm{s})$ & $16.5(11.6)$ & $21.4(8.2)$ & $21.0(9.3)$ & $24.5(12.6)$ \\
\hline Berg Balance Scale & $34(16)$ & $31(19)$ & $39(9)$ & $53(20)$ \\
\hline
\end{tabular}

Abbreviations: CG: Control Group; EG: Experimental Group; PL: Paretic Limb; NPL: Non-Paretic Limb; IQR: Interquartile Range; 


\section{Movement Analysis Profile}

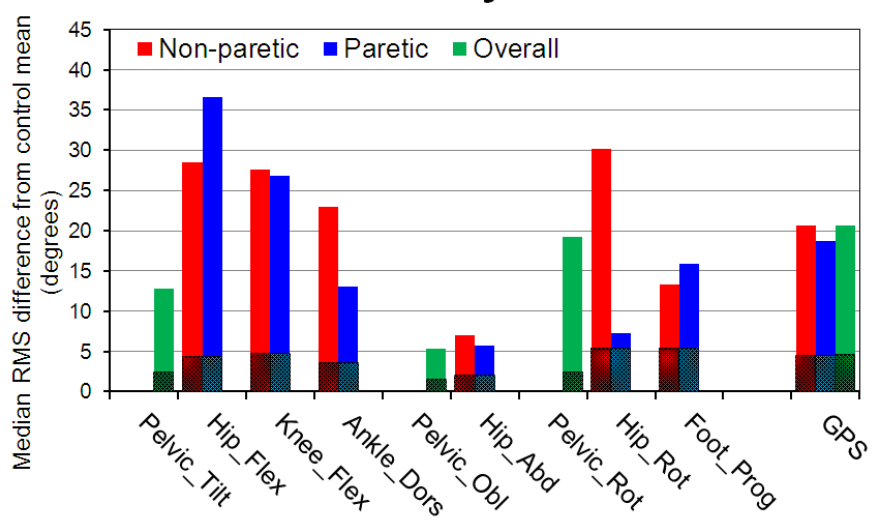

Figure 2. Example of Movement Analysis Profile (MAP). The dark part of the bars corresponds to the reference values from healthy subjects

Table 7. Distribution of the participants across the levels of the Functional Ambulation Category (FAC)

\begin{tabular}{|l|c|c|}
\hline Functional Ambulation Category (FAC) & $\begin{array}{c}\text { CG } \\
\text { Pre / Post }\end{array}$ & $\begin{array}{c}\text { EG } \\
\text { Pre / Post }\end{array}$ \\
\hline FAC 1 - Continuous manual contact for ambulator & $2 / 0$ & $0 / 0$ \\
\hline FAC 2 - Slight manual contact to ambulator & $0 / 0$ & $0 / 0$ \\
\hline FAC 3 - Ambulator on supervision & $0 / 0$ & $4 / 0$ \\
\hline FAC 4 - Ambulator only level surface & $3 / 2$ & $2 / 1$ \\
\hline FAC 5 - Independent ambulator & $2 / 5$ & $3 / 8$ \\
\hline
\end{tabular}

Abbreviations: FAC: Functional Ambulation Category; CG: Control Group; EG: Experimental Group

In the EG (Table 5), there was difference for the GPS_O, the GPS_PL and the GVS Knee Flexion/Extension of the PL, whose index values decreased after intervention, showing that in this group, the values were closer to normality. Two of the 15 GVS (Knee Flexion/ Extension and Ankle Dorsi/Plantarflexion) presented the highest concentration of score improvement, while two others (Pelve Obliquity and Hip Adduction/Abduction) concentrated most of unfavorable results of EG. Such a clear division does not occur in the CG, where positive and negative results are scattered over all the variables. These findings suggest that the EG may have adopted a more homogeneous gait pattern among participants. This is consistent with those of Souza et al. [33], which published the results of a 6-week pilot study of three 45-minute weekly sessions in a sample of 12 post-stroke hemiparetic participants in the chronic phase (mean time: 4.3 years \pm 3 ). They found that various spatiotemporal gait parameters, had improved, among them the symmetry of the steps, a factor that influences the GPS results. In the same study, the authors describe improvements in the angular parameters involving the trunk and lower limbs, with an emphasis on the thigh and feet, indicating that participants had better selective control of lower limb after weight-bearing gait training on the ground.

Regarding the secondary outcome measures (Tables 6 and 7), it is possible to observe that both interventions led to improvement in the BBS and to a migration towards higher levels of the FAC. The differences in the gait speed and BBS between groups are not statistically significant probably due to the sample size and the consequent large dispersion. Another possible reason for the lack of superiority of the LTBWS program was that the intensity of the training was not the one we planned. The parameters adopted in the present study were based on a review of randomized clinical trials using some bodyweight support equipment, many of which applied treadmill and ground gait training, and started the sessions with a relief $30 \%$ to $40 \%$ of the participant's body weight $[6,9,34]$. However, despite the effort to replicate the parameters in our study, many of them could not be reproduced, such as weekly frequency, session duration and training evolution criteria. This was so, because the study was conducted in a clinical setting and the procedures were adapted to the patient's routine and not the other way around.

As we have adopted a pragmatic approach, the sample of the present research was very heterogeneous, with the participants distributed between sub-acute $(n=7)$ and chronic $(n=9)$ phase. Although changes in motor deficits are more effective in the first months after stroke [32], we suggest that the absence of conclusive responses may be related to the low frequency of interventions and not to the time after stroke. In fact, recent studies $[12,35,36]$ demonstrate that even in the chronic phase, the intensive approach can have positive results in motor rehabilitation of individuals with stroke sequelae. In the present study, patients at different stages of stroke evolved without apparent correlation with the time after stroke. Among the CG participants who presented the best results, one (U) was in the sub-acute phase (3 months) and two in the chronic phase (S, 7 months and $\mathrm{X}, 11$ months). Also, in this group, one patient in sub-acute (B, 3 months) presented only worsening exceeding $\mathrm{MDC}$ and one in chronic phase (K, 10 months) remained quite stable in all variables, not exceeding MDC in any of the observed changes.

In the EG, two of the patients with favorable evolution above the MDC, were in the sub-acute phase (J, 1 month; O, 2 months) and one in the chronic phase (R), 24 months of injury. Exclusively negative changes above MDC occurred in one patient who was in the sub-acute phase (I, 5 months) and one patient in the chronic phase (D, 10 months). Although the neurological recovery process presents a spontaneous tendency in the early post-injury phase, occurring mainly during the first months, some patients may demonstrate considerable recovery in late phases [37].

Regarding the overall evolution within the groups, we have found the changes in both of them, but only in the EG they were statistically significant for the variables GPS_O, GPS_PL e GVS_Knee Flexion/ Extension PL. This finding is encouraging, even though it might be explained by the slightly larger sample size of EG.

Two important limitations of our study were the small sample size and relatively low frequency of intervention, issues that must the overcome in future studies.

In summary, there was no difference between groups regarding GPS and GVS variables after intervention. Moreover, the improvement in the balance score and gait independence level was also equivalent. However, when looking at individuals, it was possible to observe that, in some cases, the improvement was above the MMD stablished in the literature. Therefore, associating LTBWS with physical therapy seems to be not superior than conventional physical therapy, but it deserves more investigation in larger samples as there were some individuals that responded better than others.

\section{Acknowledgement}

This work had financial support from CAPES and Araucaria Foundation (grants number 016/2011-p. 19076 and 07/2012).

\section{References}

1. Geurts AC, de Haart M, van Nes IJ, Duysens J (2005) A review of standing balance recovery from stroke. Gait Posture 22: 267-281. [Crossref] 
2. S Hesse C, Bertelt MT Jahnke, Schaffrin APT, Baake PPT, et al. (1995) Treadmill training with partial body weight support compared with physiotherapy in nonambulatory hemiparetic patients. Stroke 26: 976-981. [Crossref]

3. Detrembleur C, Dierick F, Stoquart G, Chantraine F, Lejeune T (2003) Energy cost, mechanical work, and efficiency of hemiparetic walking. Gait Posture 18: 47-55. [Crossref]

4. Visintin M, Barbeau N, Korner-Bitensky N, Mayo NE (1998) new approach to retrain gait in stroke patients through body weight support and treadmill stimulation. Stroke 1122-1128. [Crossref]

5. Barbeau H, Visintin M (2003) Optimal outcomes obtained with body-weight support combined with treadmill training in stroke subjects, Arch. Phys. Med. Rehabil 14581465. [Crossref]

6. Dean CM, Ada L, Bampton J, Morris ME, Katrak PH, et al. (2010) Treadmill walking with body weight support in subacute non-ambulatory stroke improves walking capacity more than over ground walking: A randomised trial, J. Physiother 97-103. [Crossref]

7. Mulroy SJ, Klassen T, Gronley JK, Eberly VJ, Brown DA, et al. (2010) Gait Parameters Associated with Responsiveness to Treadmill Training with Body-Weight Support After Stroke: An Exploratory Study. Phys. Ther 90: 209-223. [Crossref]

8. Ribeiro T, Britto H, Oliveira D, Silva E, Galvão E, et al. (2013) Lindquist, Effects of treadmill training with partial body weight support and the proprioceptive neuromuscular facilitation method on hemiparetic gait: A randomized controlled study. Eur. J. Phys. Rehabil. Med 49: 451-461. [Crossref]

9. Daly JJ, Zimbelman J, Roenigk KL, McCabe JP, Rogers JM, et al. (2011). Holcomb, E.B. Marsolais, R.L. Ruff, Recovery of coordinated gait: Randomized controlled stroke trial of functional electrical stimulation (FES) versus no FES, with weight-supported treadmill and over-ground training. Neurorehabil. Neural Repair 25: 588-596. [Crossref]

10. Langhorne P, Coupar F, Pollock A (2009) Motor recovery after stroke: a systematic review, Lancet Neurol. 741-754.[Crossref]

11. Hesse S, Konrad M, Uhlenbrock D (1999) Treadmill walking with partial body weight support versus floor walking in hemiparetic subjects. Arch Phys Med Rehabil 80: 421427. [Crossref]

12. Duncan PW, Zorowitz R, Bates B, Choi JY, Glasberg JJ, et al. (2005) Management of Adult Stroke Rehabilitation Care: a clinical practice guideline. Stroke 36: e100-43. [Crossref]

13. Dobkin BH, Dorsch A (2013) New evidence for therapies in stroke rehabilitation. Curr Atheroscler Rep 15: 331. [Crossref]

14. McCain KJ, Pollo FE, Baum BS, Coleman SC, Baker S, et al. (2008) Locomotor Treadmill Training with Partial Body-Weight Support Before Overground Gait in Adults with Acute Stroke: A Pilot Study. Arch. Phys. Med. Rehabil 89: 684- 691. [Crossref]

15. DePaul VG, Wishart LR, Richardson J, Lee TD, Thabane L (2011) Varied over ground walking-task practice versus body-weight-supported treadmill training in ambulatory adults within one year of stroke: A randomized controlled trial protocol, BMC Neurol 11: 129. [Crossref]

16. Dobkin BH, Duncan PW (2012) Should body weight-supported treadmill training and robotic-assistive steppers for locomotor training trot back to the starting gate? Neurorehabil. Neural Repair 26: 308-317. [Crossref]

17. Gama GL, Celestino ML, Barela JA, Barela AMF (2019) Gait initiation and partial body weight unloading for functional improvement in post-stroke individuals. Gait Posture 68: 305-310. [Crossref]

18. Gama GL, Celestino ML, Barela JA, Forrester L, Whitall J (2017) Effects of Gait Training with Body Weight Support on a Treadmill Versus Overground in Individuals with Stroke. Arch. Phys. Med. Rehabil 98: 738-745. [Crossref]
19. Davis RB, Ounpuu S, Tyburski D, Gage JR (1991) A gait analysis data collection and reduction technique, Hum. Mov. Sci 10: 575-587.

20. Baker R, McGinley JL, Schwartz MH, Beynon S, Rozumalski A, et al. (2009) The gait profile score and movement analysis profile. Gait Posture 30: 265-269. [Crossref]

21. Beynon S, McGinley JL, Dobson F, Baker R (2010) Correlations of the Gait Profile Score and the Movement Analysis Profile relative to clinical judgments. Gait Posture 32: 129-132. [Crossref]

22. Devetak GF, Martello SK, de Almeida JC, Correa KP, Iucksch DD, et al. (2016) Reliability and minimum detectable change of the gait profile score for post-stroke patients, Gait Posture 49: 382-387. [Crossref]

23. Fukuchi CA, Duarte M (2019) Gait Profile Score in able-bodied and post-stroke individuals adjusted for the effect of gait speed. Gait Posture 69: 40-45. [Crossref]

24. Miyamoto ST, Lombardi Junior I, Berg KO, Ramos LR, Natour J (2004) Brazilian version of the Berg balance scale. Braz J. Med. Biol. Res 37: 1411-1421. [Crossref]

25. Mehrholz J, Wagner K, Rutte K, Meissner D, Pohl M (2007) Predictive Validity and Responsiveness of the Functional Ambulation Category in Hemiparetic Patients After Stroke, Arch. Phys. Med. Rehabil 88: 1314-1319. [Crossref]

26. Baker R, McGinley JL, Schwartz M, Thomason P, Rodda J, et al. (2012) The minimal clinically important difference for the Gait Profile Score. Gait Posture. 35: 612-615. [Crossref]

27. R. Baker, MAP and GDI calculators, Wwrichard.Net. Available at http://wwrichardnet resources/gps-map-and-gdicalculators/.

28. Daly JJ, Sng K, Roenigk K, Fredrickson E, Dohring M (2007) Intra-limb coordination deficit in stroke survivors and response to treatment. Gait Posture 25: 412-418. [Crossref]

29. Sullivan KJ, Brown DA, Klassen T, Mulroy S, Ge T, et al. (2007) Effects of TaskSpecific Locomotor and Strength Training in Adults Who Were Ambulatory After Stroke: Results of the STEPS Randomized Clinical Trial. Phys. Ther 87: 1580-1602. [Crossref]

30. Lamontagne A, Malouin F, Richards CL (2001) Locomotor-Specific measure of spasticity of plantar flexor muscles after stroke. Arch. Phys. Med. Rehabil 82: 16961704. [Crossref]

31. Trompetto C, Marinelli L, Mori L, Pelosin E, Currà A, et al. (2014) Pathophysiology of spasticity: Implications for neurorehabilitation. Biomed Res. Int 2014: 1-8.

32. Formisano R, Pantano P, Buzzi MG, Vinicola V, Penta F, et al. (2005) Late motor recovery is influenced by muscle tone changes after stroke. Arch Phys Med Rehabil 86 308-311. [Crossref]

33. Sousa CO, Barela JA, Prado-Medeiros CL, Salvini TF, Barela AM (2011) Gait training with partial body weight support during over ground walking for individuals with chronic stroke: A pilot study. J. Neuroeng. Rehabil 8: 48. [Crossref]

34. Yen CL, Wang RY, Liao KK, Huang CC, Yang YR (2008) Gait training-induced change in corticomotor excitability in patients with chronic stroke. Neurorehabil. Neural Repair 22: 22-30. [Crossref]

35. T. Takao, N Tanaka, N. Iizuka, H. Saitou, A. Tamaoka, et al. (2015) Improvement of gait ability with a short-term intensive gait rehabilitation program using body weight support treadmill training in community dwelling chronic poststroke survivors. $J$ Phys. Ther. Sci 27: 159-163. [Crossref]

36. Middleton A, Merlo-Rains A, Peters DM, Greene JV, Blanck EL, et al. (2014) Body weight-supported treadmill training is no better than over ground training for individuals with chronic stroke: A randomized controlled trial. Top. Stroke Rehabil 21: 462-476. [Crossref]

37. R Bonita, Beaglehole R (1988) Recovery of motor function after stroke, Stroke 19 1497-1500. [Crossref]

Copyright: (C2019 Manffra EF. This is an open-access article distributed under the terms of the Creative Commons Attribution License, which permits unrestricted use, distribution, and reproduction in any medium, provided the original author and source are credited. 